\title{
THE PERSPECTIVE OF THE NEWLY IMPOVERISHED CITIZENS IN THE REPUBLIC OF MACEDONIA
}

\begin{abstract}
Poverty is a multidimensional phenomenon that corresponds to certain living conditions, that is the inability to participate in the social life of the community we belong to. There have always been poor people all over the world.

Several years-long measurements and qualitative analyses of poverty in the Republic of Macedonia have enabled the identification of the basic profiles of poor citizens.

Based on the poverty measurement and the analysis in the Republic of Macedonia, we can discuss three profiles of poor citizens: traditionally poor, chronically poor, and newly impoverished.

Based on Mill's work, this study is focused on micro-sociological research related to poverty in the Republic of Macedonia.

Accepting the indisputable fact that every social occurrence is related to the social structure one way or the other; this study analyzes the newly impoverished citizens. Special attention is given to their status and role in the Republic of Macedonia.
\end{abstract}

Key words: newly impoverished citizens, social structure, status, and roles.

\section{Introduction}

Social development history shows that the egalitarian society is an unfulfilled dream for many theoreticians. Namely, excluding the gendered society, different forms of social inequality are present in almost all types of society. However, it seems that the social inequalities foundation has been laid with the private property and the definitions of the classes of rich and poor. The class distinction refers to the uneven distribution of the material and other resources which are necessary for a decent life. Today, many people live in poverty in such circumstances (Jeffrey D. Sachs, 2015).

Our interest in this study is focused on that structural form of socially created inequality - poverty.

Poverty is a multidimensional phenomenon that corresponds to certain living conditions, which means the inability to participate in the social life of the community we belong to. Poor are considered to be people, families, and groups of people whose resources (material, cultural and social) are at such a 
level that excludes them from the minimally acceptable manner of living in the country they live (http://epp.eurostat.ec.europa.eu).

World Bank assesses that today 1,5 million people live in extreme poverty in the Western Balkan (http://www.utrinski.mk).

With the transition to market economy in 1991, the Republic of Macedonia marked the start of the long and socially difficult transition. The transition process was accompanied by privatization, enterprise restructuring, and the closing of numerous non-profitable industrial capacities. Consequently, a large part of the workforce in the Republic of Macedonia became redundant. The unemployment and poverty rates drastically increased; simultaneously the living standards significantly worsened. In such a situation, poverty and social exclusion as complex and multidimensional problems were accompanied by human rights negation, which points to the fact that the vulnerable population could not satisfy their basic living needs (Donevska, M. et al. S.2011:10).

According to our research, throughout the transition period up to now, the most vulnerable groups that are at risk of impoverishment in the Republic of Macedonia are the following: unemployed people without any or with elementary education; employed people without education and qualifications; people with low-level education, people on the poverty borderline; people in a long-time work search; families with underage children; families with a higher number of members and unemployed newly-married couples.

Years-long measurement and qualitative analyses of poverty in the Republic of Macedonia have enabled the identification of three basic profiles of poor citizens: traditionally poor, chronically poor, and newly impoverished (Marija, D. Vesna D. Blagica N. 2011:113).

The newly impoverished families are "victims" of the transition processes in our country. This group of poor people includes family members who have been unemployed for a long time or are employed but with low or irregular salaries. Most of the redundant workers also belong to this group of poor citizens.

These families often have no income or their actual income is extremely low. Most often, they are families that used to belong to the middle social class. Interestingly, this profile involves poor citizens with a college or university degree. Most of them, however, have a high school diploma (Dimitrievska, 2015).

We do not wish to dispute the scientific assumptions regarding the connection of the economic welfare in the transition period until now and the condition of poverty, nor to discuss the socially created inequalities which contributed to the increase of poor families, and the process of privatization.

Our interest is towards the analysis of the perspective of the newly impoverished families in the Republic of Macedonia.

For that purpose, the interaction between the members of the newly impoverished families is analyzed: inside their primary family, between their relatives, friends, and the social groups they communicate with. 
The study is looking for the answer to the questions: What is the position of these families in the social structure? How do the newly impoverished family members act with the other people from the community? Does the longterm condition of poverty recruit the second generation of poor families? Do the newly-born members get predetermined status? What is their status on the micro-level of the social structure (their family, peer group, institutions they work in, etc) as well as on the macro level?

For accomplishing the goals, data from the State Statistics Office of the Republic of Macedonia and relevant data from other scientific research have been used. For the needs of this study, the author also uses data from the life quality research of 420 poor families (Dimitrievska, 2008:51).

The conclusion on the perspectives of the newly impoverished families is supported by data obtained from qualitative research which was conducted among 30 newly impoverished families.

Guided by the goals, a panel longitudinal research draft for the thirty families has been used for the period of 2002, 2005, 2010, and 2015.

A case study for three newly impoverished families has been carried out within the conducted research.

\section{Research results}

The data analysis of the panel longitudinal research, which was conducted among the thirty newly impoverished families, refers to the following conclusion with regards to the member interaction.

\subsection{Poor members interaction in years 2000, 2005, 2010, 2015}

The matters related to the interaction of the social groups are one of the fundamental matters in sociology. In the sociological literature, there is no unanimous opinion regarding the social group interaction classification. The division of conjunctive and disjunctive interaction processes is acceptable for us (Fiamengo, 1977:286).

The main conjunctive process forms of social group interaction are: cooperation, accommodation, and assimilation. The basic disjunctive process forms of interaction (division processes) are competition and conflict (Fiamengo, 1977:287).

The analyses of the results related to the interaction of the newly impoverished families in 2000 say that it is an adjustment period of these families to the new conditions. The conjunctive processes of interaction with the family members, friends, and relatives are mainly within cooperation. These families show mutual respect and develop friendly relations in their individual or group interest fulfillment processes.

The beginnings of parent authority decrease are noticeable on a micro-level of the social structure. The new condition very often puts these family members in a situation where they cannot satisfy their basic material, cultural 
and social needs. The parents strongly feel responsible for the new condition. This can sometimes lead to disjunctive interaction among the members of the newly impoverished families. The disagreement between the children and the parents especially the fathers is noticeable. Their interaction is usually accompanied by verbal conflicts.

The attitudes of the children from the newly impoverished families are concerning. Namely, they consider themselves not preferred among peers which are in better financial standing. With regards to the social grouping, the analysis of the data for 2000 points out that most of the children from the newly impoverished families spend time with children with similar financial standing.

\section{The interaction of the grown members with members of other social groups is interesting.}

For example, when looking for a job, it is visible that most of the adult members are trying to adjust to the members of those groups, although that process of adjustment as they say "is humiliating and increases the already present feeling of powerlessness and injustice". This feeling has its influence on the disjunctive processes of interaction too, which is accompanied by verbal fights.

The employed members of these families feel the change in their status at work. The conjunctive processes of interaction with people in managing positions are in adjustment form.

It is really remarkable that in the communication with people outside their closest family, the newly impoverished people often adjust to the conditions imposed by others. That adjustment process, as most of the researched people say, is difficult to handle, especially at work.

In the coworker interaction processes, most of the newly impoverished people consider that there is no cooperation between them and the other employees in the companies they work in. Their obedience towards the managers is noticeable. This attitude is due to the fear they feel of being fired.

Most of the adult members of the newly impoverished families feel that the new situation conditions a change in their social status. The fact that in this period they still try to act in accordance with the roles they had before impoverishing is interesting. Such behavior is usually accompanied by their internal conflict. This occurrence is more evident among the older members of the newly impoverished families.

With regards to the social position of the newly impoverished families, which has been observed through Weber sociological paradigm (Petrovska, B. et al.: 1998, 275), a change of wealth and power is evident. However, with regards to the reputation of these families, no noticeable changes can be identified. Most of the analyzed families in this period still have goods and services at their disposal, they come from middle-class families, they have a high school or 
higher education diplomas. Their social status is still inconsistent (Haralambos, 2002:22290).

As a consequence of the unchanged material condition in 2005, there are changes in the interaction among the family members, especially between the spouses, but also with the other social groups. The husband's role (as the family head) in the family weakens. The interactions with friends weaken. There are insignificant changes in the interactions with relatives and siblings. There is an increased revolt of the family members towards some institutions (employment agencies, health institutions, power and water supply companies, others).

In this period, the interactions of the newly impoverished family members with their families, relatives, and friends are mainly within cooperation. This is also the period when the conjunctive processes of interaction with the members of the closest family and relatives begin to weaken.

On a micro-level of the social structure, there is a noticeably decreased interaction with the other social groups. The conjunctive processes of interaction are mostly directed towards adjusting to the condition these poor families are in. With regards to the disjunctive processes of interaction, there is an increased absence of competitive interactions among almost all members of these families. The responsibility for their unchanged conditions they locate with the politicians. In this period, there are visible cooperative interactions among bankruptcy workers for exercising their individual/group interests manifested through strikes.

However, based on the conversations with the adult members of the newly impoverished families, we cannot say that the conflicts, the disjunctive processes of the bankruptcy workers are in the direction of changing their condition. On the contrary, most of the researchers think that going on a strike can worsen their already bad condition.

From the informal conversations with some members of the newly impoverished families with regards to the bankruptcy worker strikes, we got the impression that they are afraid of the government, that they are manipulated by the strike organizers and they do not consider the strike as a means of improving the bed condition.

In this period, most of the children in the researched families are completing their education and are looking for a job. We must highlight their revolt and the sense of helplessness, as they say, "everything is a consequence of the low social status our families have in the country". It is difficult for them to face everyday challenges. Some of them try to find their luck out of the country. For some of them, seasonal migrations to other countries are the solution to their problems. It is interesting that most of the adult children from these families do not consider forming their own families (they do not want to talk about marriage). The changes in the interactions with other children are visible in this period. The children of these families most often socialize with the children from their family and with those similar to them. 
The adult members find it more and more difficult to get a job. They most often face problems that arise from their ineligibility for the labor market, but also due to their age and lack of political party involvement. What they indicate as a problem is also the money without which they cannot requalify. They experience a strong sense of powerlessness in this period. This, in turn, influences their "imprisonment in the vicious cycle of poverty." Actually, their conjunctive processes of interaction outside their family are turning into adjustments to other social groups. Some of the employed people are now unemployed. Some of them started their own business but it is not going well. The social position of the newly impoverished families is significantly changed with most of the analyzed families in this period. The lack of money is strongly felt in this period. Most of the newly impoverished families sell their valuables from their properties. They take more and more loans from friends, relatives, they are indebted to the sellers where they buy with deferred payments, banks, and others.

The cooperative interactions with relatives and friends start to weaken. Disjunctive processes of interaction among the family members are evident, accompanied by conflicts. Psychological problems among the family members appear.

Most of the family members have low-status consistency.

In 2010 there are much more changes, especially among the families which have no changes with regard to their poverty condition. There is an apparent closeness in the interaction with the other family members.

In this period, the conjunctive processes of adjustment to other social groups are a problem for the newly impoverished citizens. The mutual standards of the desired behavior among the family members and outside of them are usually not followed. Other people outside their family start avoiding them. Their low-status consistency worsens.

Most of the children that can work have not found a job yet. Although they are adults, they do not think about forming their own families. The ones who got married face the problem of impoverishment again. That is especially noticeable with the ones who have children. Most of the newborns have predetermined statuses (poor children).

The research results indicate that in 2015 the given findings have already worsened with most of the newly impoverished families. Especially worrisome is the fact that closeness exists inside the closest family. The interactions outside the family are minimal. It is interesting that there is a strongly expressed cooperation among the members of the closest family. One can get the impression that the members are united. However, based on the informal conversations "that is a forced condition so they can survive". The condition which has not changed in 15 years created a specific living culture, more precisely, "adaptation to the condition of poverty". One might get the impression that there is a lack of desire to "fight" for a better future. Their passiveness in the interactions 
is typical. Especially worrisome is the increase in the number of second-generation poor members.

The depicted situation will be accompanied by three life stories of the newly impoverished members in the Republic of Macedonia.

\subsubsection{Case 1}

The following analysis is made in relation to the family head.

One of the many newly impoverished families in the Republic of Macedonia is the family Markovski. This family has four members. The husband was born in 1957. He was employed in glassworks Gostivar as a warehouse manager. He has a 19-year of work experience. He graduated from high school. His wife was born in 1959. She graduated from high school. The son was born in 1979. He graduated from secondary economics school. The husband's father who is retired also lives with them.

\section{Living conditions (2000)}

They live in a $60 \mathrm{~m}^{2}$ apartment. They got it from the factory where the spouses worked. Now they buy it off. It is well furnished. Most of the household items are bought after their wedding. The problems, as the spouses emphasize, started in 1989 when the wife was fired as a redundancy. In their opinion, it was without a reason.

The apartment maintenance "becomes a problem" according to the husband. They "used to paint it every year, now every fourth year or longer", he says. They use wood for heating and collect it themselves (with a permit). They regularly pay the bills. The power consumption is minimal. They have a car, make Fiat, which is 20-year old. It is used only purposefully. They mostly use it to get to the village where the wife's mother lives. Namely, she provides them with various food products.

\section{Living conditions (2015)}

They still live in the same apartment, there is nothing new, the things are already worn out. They have a new television, as they say, "the state made us buy it, by changing the carrier, we could not watch a single channel on the old TV". They can't pay the apartment installments and the bills regularly. In this period, the wife's mother and the husband's father died. Now they do not have the father's retirement money nor the additional income from the village.

\section{How this family handles life in the period 2000-2015}

Starting from 1989, when after blackmailing the wife (to either leave her job or return the apartment), according to the spouses, their living conditions 
have been going downhill. He also becomes redundant in 2004. Since then, they have been living with the husband's father minimal retirement money, and help from the wife's mother. Soon this family has no income. The father dies, and very soon the wife's mother as well. They sometimes contribute to their family budget by collecting medicinal plants. However, that income today (2015) is denied. Namely, as they say, they need a permit to gather plants. In order to get it, a certain amount of money should be paid. According to the husband, "even if we borrow money, we might not get it, certain people usually get it. On top of everything, the placement of the plants is impeded, more often than not the plants rot".

At the beginning (2000) 75\% of the family budget of this household was spent on food, $5 \%$ on bills, and the remaining $20 \%$ on hygiene, clothes, petrol, woods, others. In 2015, the condition is worrisome, this family lacks means. They spend money on food, but they lack it for other needs. As they say, "We used to have friends and borrowed some money, clothes, food and other things from them. Today, everyone is running away from us, no one lends us anything. Even the store owners, where most of the neighbors bought things with deferred payments, do not give us anything. They know we have difficulties in returning the debt. Our relatives also avoid us. We have almost no communication with no one".

\section{The youth and education (2000-2015)}

After completing high school, the son did not continue his education. Socializing with friends, outside the home, become a bigger problem with each passing day. As he says, "I am ashamed of going out, I cannot pay for a single drink". He is looking for a job, but he can't find permanent employment. He works without choosing, but not as an economic technician. He was abroad as well, but he had no success. He has no girlfriend, the condition of his family, as he says "strongly influences me, I lack self-confidence".

He is not married yet, has no girlfriend nor permanent employment. He also became a political party member, worked a lot for the party, he was not given the things promised. He spends his days home.

\section{Health and hygiene (2000-2015)}

Thanks to the good planning, the hard work, and the cooking skills of the wife, the nutrition in the family is good. Every day the wife prepares different stews, bakes bread at home, prepares pickled vegetables. They collect fruits from the mountains and she makes juices, jams, others. The food they use at home is mostly homemade or bought at the stores which have the lowest prices and mostly they buy in bulk. products.

The hygiene is at a satisfactory level. They do not use expensive hygiene 
This family has not changed the routines in the period until 2015. Today (2015), the lack of products for cooking is quite obvious. Their food is monotonous.

The spouses' health is disturbed. The wife has high blood pressure and rheumatic problems, he has heart problems. The son has psychosomatic disorders.

The social consequences this family suffers in this period do not refer to the family relations but in the lifestyle. The last time they went on holiday was in 1990. From 2000 to 2015 they consistently weaken social communications. In the beginning, they tried to go wherever they were invited (weddings, birthdays, other) thereby cutting down their already small budget or giving something they already had (for example, bed linen). Today they go almost nowhere. As they say "the relatives and family do not invite us, because they know we are beggars."

\subsubsection{Case 2}

The following analysis is made in relation to the family head.

The family Georgievski has four members. The "head of the family" is 41 years old in 2000. He is a bankrupt worker and has a college degree. The wife is 38 years old and also a bankrupt worker. She graduated from high school. The family has two daughters (14 and 12 years old). One is in her first year in high school, the second is in the seventh grade. The mother and the father also live with them.

\section{Living conditions (2003)}

They live in an $80 \mathrm{~m}^{2}$ house with the father, mother, the younger brother, and his wife. It is well furnished but very small. The wood they collect on their land in the countryside is used for heating. They regularly pay the bills.

\section{Living conditions (2015)}

Thanks to the parents' help, they live in their own $42 \mathrm{~m}^{2}$ apartment. It is equipped with the necessary appliances and furniture. They regularly pay the bills.

\section{How this family handles life in the period 2000-2015}

After the spouses were left unemployed, they found themselves in a very difficult situation. Thanks to their parents and their craftiness, they managed to improve their life. In the beginning, they worked on their fields in the countryside, they kept bees and collected mushrooms. For a period of time, the husband worked on a toll road, but as he says "I was fired because of my political 
affiliation". With the help of friends, parents, and bank credit, today this family has its own taxi company with 3 vehicles.

\section{The youth and education}

The first daughter is in her first year in high school, the second one is in the seventh grade. They are excellent students and have a positive attitude towards school and have aspirations for continuing their education. They have no obstacles in interaction with the family members and outside it. They socialize with peers from the neighborhood, school, and their wider circle.

Today, the older daughter is graduated from the faculty of electrical engineering. She helps in the family company and tries to find a job based on her vocation. The younger one is finishing the studies at the faculty of economics in Skopje.

\section{Health and hygiene}

Thanks to the good organization and harmony of all adult family members, especially the mother, the wife and the brother's wife, the nutrition in this family is very good. Different meals are prepared every day. This household prepares a lot of pickled vegetables (they make home juices, jams, homemade wine, and schnapps). The foods they use are mostly home-grown.

Fifteen years later, the habits of this family have not changed regarding food preparation. The wife still puts a lot of effort and skills into preparing good food, making pickled vegetables, and taking care of the home, although she is very involved in their company.

The hygiene is at a satisfactory level.

\section{The health condition}

They do not have more significant problems. Except, as the wife says, "Today (2015) we are exposed to much bigger stress, we are self-employed. The private business is very unpredictable, but we don't complain, at least we earn money, we don't wait for something from the others, that's why our blood pressure can vary".

The social consequences this family experiences in this period do not refer to the relations with family, relatives, and friends, but to the lifestyle which correlated with their condition of poverty. At the beginning of the researched period (2015), there was a tendency for decreased or minimal social communication. Only the girls went on vacation, mostly if it was organized by the school. The birthday invitations, celebrations, and other events were often avoided. Today (2015) the condition is changed, but as they say, they have no time for 
socializing, they leave it up to the children. As the husband says, "We go only if we cannot avoid it".

\subsubsection{Case 3}

The following analysis is made in relation to the life in the family.

This family consists of four members. The husband is 47 years old in 2000 and is a bankrupt worker, he has a high school diploma. The wife is 44 years old and left the public administration willfully. Now she works as a cosmetician, she graduated from high school. The family has two children (16 and 13 years old). The daughter is in her third year in high school, the son is in the eighth grade.

\section{Living conditions}

In 2000, they live in a house, property of the wife's mother. The house is equipped averagely. There are no significant changes since the house was built. They pay the bills regularly.

They live in the same house, but there are drastic changes in the living conditions of this family. Nothing has been renewed in the house, it is literally falling apart. Their belongings are ruined, and more valuable ones were sold. They do not have a new television, the washing machine has long been broken, as the owner says, "I cannot buy, I am up to my neck in debts". Their electricity has been cut off for a longer period.

\section{How this family handles life in the period 2000-2015}

Since 2000, this family lives with the money the wife makes and the minimal retirement money from her mother. She earned well for a period. The income she made was gradually decreasing. The husband worked here and there but he could not find permanent employment.

Today (2015) they are divorced. This family has no income. The wife's mother died 8 years ago. Until now, the family has not submitted a request for social assistance, as she says because she was embarrassed. But the difficult and hopeless situation made her go against her principles and is now in the procedure for getting monetary social assistance.

\section{The youth and education}

The daughter is in her third year in high school and the son is in the eighth grade. These children spend almost no time with their peers.

(1) In this period, the daughter starts working in cafes, she often spends her nights with suspicious clients, consuming certain narcotics. She enrolls at 
the Faculty of Law but has not finished it yet. Now we have no contact with her, says the mother, she lives with her father.

The son finishes high school in this period, from time to time he works for the neighbor who has a private company (more out of compassion rather than a real need for that type of worker). The son communicates with almost no one, he is very closed.

\section{Nutrition, health, hygiene}

In the beginning, this family had no problems with nutrition, thanks to the help from the mother, who supplied them with food and often cooked for them. But as this family was going into poverty, their nutrition was becoming worse and worse. The initial reason was lack of funds, but the mother's careless expenditure as well. When she has money she spends it irrationally, when she does not she starves. According to the wife's statement, lately, she drinks only water several days in a row.

In the beginning, the hygiene was at a satisfactory level. But it is worrisome today.

The health condition was stable, now it is disrupted, mostly the wife's.

Consequences: In the researched period 2000 to 2015 this family has been in complete decay. The parents are divorced. The daughter has taken a bad path (narcotics, prostitution). The son is self-isolated, does not communicate with anyone, has no girlfriend, no job. The mother tried to find the exit from the difficult situation in prostitution but she failed and got morally ruined.

\section{Concluding findings}

Based on the given findings from the panel longitudinal research and the three cases, the conclusions and recommendations follow:

- It is indisputable that the newly impoverished families have a bad quality of life by the fact that they are poor. Their living quality is in direct correlation with the poverty condition duration. The longer the condition of poverty lasts, the bigger the risk of worsening of their living conditions, social communication, functional disturbances, psychosomatic illnesses, and psychological problems is.

- The newly impoverished families which do not experience any visible changes (positive) become more estranged and distant from the regular flows in the Republic of Macedonia. Their social exclusion becomes more and more visible.

- The poverty condition duration affects the types of interactions of these family members. The interaction with the family members, friends, and relatives is mostly within cooperation. As time goes by, so the interaction with the family members turns into antagonism. 
Especially distinguishable are the disagreements between children and parents. Verbals conflicts often follow their interaction.

- The role of the husband (the family head) most often weakens in these families.

- The poverty condition duration influences the interactions with friends. The longer the poverty condition, the weaker the interactions with friends. The cooperative interactions with friends and relatives also weaken.

- The poverty condition duration negatively influences the interaction with other social groups on the micro level of the social structure.

- The cooperative interactions between bankruptcy workers for exercising the individual/group interest, manifested through strikes, do not reflect the real need of the newly impoverished families.

- Most of these family members have low-status consistency.

- The unchanged condition, especially of the families that have experienced no changes regarding their poverty condition, affects the more visible closeness of the members of the newly impoverished families in relation to the interaction with other members outside their families. In this period, the conjunctive processes of adjusting to other social groups become a problem for the newly impoverished citizens. The others outside their family start to avoid them. Most of the newborns get a predetermined status (poor children).

- The poverty condition duration contributes to the deepening of the new consistency status of the members of the newly impoverished families.

- A long period without changes in the poverty condition imposes a need for restrengthening of the cooperation among the closest family members.

- The fact that there is an increased number of the second generation of poor members and that it deepens their low consistency status is worrisome.

- Numerous poverty experts say that education investment is an efficient solution for reducing poverty. However, the research results indicated the conclusion that the poverty condition duration affects the parents' and childrens' attitudes towards education. Namely, if the period of poverty is longer than the parents' attitudes for their own and their children's education change from positive to negative.

- The longer the period of poverty, the higher the risk of self-isolation among these family members. The findings regarding social grouping are worrying. Namely, these children spend most of their time with children similar to or same as them.

The given findings have directly indicated the answers to the questions: What is the position of these families in the social structure? How do the members of the newly impoverished families act with the other people from the 
community? Does the long-term poverty condition of these families recruit the second generation of poor families? Do the newborn members have a predetermined status? What is their status on a micro-level of the social structure (their family, the peer group, the institutions where they work) as well as on a macro level?

There is an indisputable conclusion that the newly impoverished families, which have not changed their status, become socially excluded in our country. Namely, the results indicated that most of the researched families become estranged and distanced from the normal societal flows because of the inability to effectively participate in the economic, cultural, and social life of the Republic of Macedonia.

However, the perspective of the newly impoverished families is in building and fully implementing a wider and more effective action for overcoming the undesirable conditions that are met by the newly impoverished family members in the Republic of Macedonia.

\section{Bibliography}

Dimitrievska V.(2008), Vlijanieto na obrazovanieto vrz stavovite na siromashnite semejstva i faktorot obrazovanie (The influence of the education on the attitudes of the poor family and the factor education), Godishen zbornik, Faculty of Philosophy, Skopje

Dimitrievska, V.(2015). Qualitative analysis of the newly impoverished families in the Republic of Macedonia, Journal of Social Policy, 11/2

Donevska, M. Dimitrievska, V. Novkovska, B. (2011). Poverty - the conditions in Macedonia. Skopje: Faculty of Philosophy

Donevska, M et al. (2011). Study on poverty and social exclusion in the Republic of Macedonia, Local social problems and needs, Skopje: Mozaik

Fiamengo,A. (1977), Osnove opće sociologije. Zagreb: Narodne novine

Jeffrey D. Sachs (2015). The End of poverty economic possibilities for our time, New York

Harlambos, M. Holborn, M. (2002). Sociologija (Sociology). Zagreb: Golden marketing

Nikolovska Natalija, Davkova S. Gordana (2001) Makedonskata tranzicija vo defekt (The Macedonian transition in defect), Skopje: MAGOR.

Petrovska, B. et al. (1998). Sociologija (Sociology). Skopje: NIP "Studentski zbor" Šućur, Z. (2001). Siromaštvo (Poverty), Zagreb

http://epp.eurostat.ec.europa.eu

http://www.utrinski.mk/?ItemID=9EFF00E2F4194E4290DE18C17CC81

6E112.07.2012, 17:43 